\title{
HERÓDOTO E AS MULHERES EGÍPCIAS: A CONSTRUÇÃO DOS COMPORTAMENTOS FEMININOS NO SEGUNDO LOGOS DAS HISTÓRIAS
}

Nathalia Monseff Junqueira ${ }^{1}$

\begin{abstract}
Resumo
Com o objetivo de apresentar novas possibilidades de se estudar as mulheres na Antiguidade Clássica, englobando as discussões da História Cultural, estudos de gênero, identidade e subjetividade dos sujeitos históricos, escolhemos como fonte para esse artigo a obra do historiador grego Heródoto de Halicarnasso, que escreveu Histórias no V a.C. Nossa intenção é a de analisar as passagens que selecionamos no Livro II em que as mulheres egípcias são relatadas em diversas situações, procurando evidências de que esse historiador compartilharia de um ideal de mulher que poderia fazer parte do imaginário de uma parcela da população masculina ateniense. Assim, demonstramos a maneira como esse padrão de comportamento feminino aparece na nossa fonte e como outras práticas sociais femininas poderiam habitar o mesmo mundo imaginado para as mulheres no mundo antigo.
\end{abstract}

\section{Palavras-chave}

Egito; Grécia; História Antiga, gênero, Heródoto.

\footnotetext{
1 Professora Doutora, Universidade Federal do Mato Grosso do Sul, Corumbá, Brasil. E-mail: nathmj@gmail.com
} 


\begin{abstract}
Aiming at the presentation of new possibilities in studying the women in the Classical Antiquity involving the discussions of the Cultural History, gender studies, identity and subjectivity of the historical subjects, we have chosen as a source of such article the work of Herodotus from Halicarnassus, the Greek historian, who wrote Histories in the fifth century B.C. Our intention is to analyze the selected passages in Book II in which the Egyptian women are presented in several situations, searching for evidences that this historian would support an ideal of a woman which could be part of the imaginary of a great deal of the Greek male population. Thus, we intend to demonstrate the way female behavior is represented in our source and how varied feminist social practices could be present in the same imagined would for women in ancient world.
\end{abstract}

\title{
Keywords
}

Egypt; Greek; Ancient History; gender, Herodotus. 


\section{Considerações iniciais}

De acordo com Keith Jenkins (2005: 23), os discursos não criam o mundo, mas eles se "apropriam do mundo e lhe dão todos os significados que têm". Partindo dessa premissa, buscaremos, nesse artigo, interpretar a representação que Heródoto faz das mulheres egípcias em sua obra Histórias, pois, nesse documento, podemos observar como a categoria do feminino e o comportamento esperado para essas mulheres foram construídos através da interação cultural, social e de poder que permeava a sociedade ateniense.

A escolha do segundo livro dessa obra, que descreve o Egito, ocorreu devido ao fato de Heródoto explicitar que os egípcios teriam os costumes diferentes de todos os outros povos (II.35), bem como descrever, de forma mais detida, esses costumes. Assim, para examinar a nossa hipótese de trabalho, de que o historiador grego compartilharia com uma parcela da população masculina ateniense um modelo de comportamento que as mulheres deveriam seguir, decidimos selecionar algumas passagens mais significativas dessa obra em que as egípcias são relatadas. A nossa seleção dessas passagens baseou-se, em grande parte, na possibilidade de dialogar com a expectativa de construção de papéis sociais femininos e masculinos na sociedade antiga e que as decisões de relatar determinados acontecimentos, por parte de Heródoto, reforçariam um ideal de mulher que deveria ser seguido por elas, ou seja, as escolhas que ele faz ao longo do relato não seriam uma ação aleatória. O que pretendemos é, a partir da análise dessas passagens, interpretar o mecanismo usado por Heródoto para relatar essas mulheres, através da sua seleção dos eventos a serem descritos e, ao mesmo tempo, mostrar que ele tinha a oportunidade de visualizar outras práticas femininas na sociedade ateniense, mas que em poucos momentos são consideradas em sua narrativa.

\section{Heródoto, sua trajetória e sua obra}

Os historiadores têm, infelizmente, poucas informações a respeito da vida de Heródoto e sobre a redação de sua obra, Histórias. Em sua única obra preservada, ele não faz menção a assuntos particulares de sua vida. Segundo David Asheri (Asheri; Lloyd; Corcella, 2007: 01), sabemos apenas o seu nome e sua cidade de origem através das primeiras palavras escritas no prólogo de sua obra:

Esta é a exposição das investigações de Heródoto de Halicarnasso para que os feitos dos homens não sejam esquecidos no tempo, e para que não percam a 
sua glória as grandes e admiráveis ações, tanto dos bárbaros quanto dos gregos; e, sobretudo, os motivos que levaram a guerrearam uns contra os outros. (Histórias, Prólogo).

Heródoto teria nascido entre os anos de 484-480 a.C. ${ }^{2}$ em Halicarnasso, atual Bodrum, região da Turquia. Halicarnasso foi originalmente uma cidade caria e dórica. A cidade tinha uma vida comercial intensa devido ao comércio de produtos realizado através do seu porto (Hart, 1982: 159). Ele teria vivido entre os principais conflitos gregos do $\mathrm{V}$ a.C.: primeiro, as Guerras Pérsicas (499-479 a.C.), contra os persas, e a Guerra do Peloponeso (431-404 a.C.), contra Esparta. Não há muitas informações sobre os primeiros anos de sua vida. Como afirma a tradição, ele foi exilado de sua terra natal por ter se unido em oposição a Ligdamis, buscando refúgio em Samos, uma cidade que era membro autônomo da Liga de Delos desde 478 a.C. Ele regressou a Halicarnasso depois do golpe que teria expulsado aquele governante do poder, que parece ter ocorrido no ano de 454 a.C. (Waters, 1996: 10; Asheri; Lloyd; Corcella, 2007: 03). Depois desse período, Heródoto teria viajado por diversas regiões próximas ao Mar Mediterrâneo e ao Mar Vermelho; estaria em Atenas em 445-4 e, depois, teria partido para Túrio, onde se tornou cidadão, falecendo aproximadamente na década de 420 a.C.

Essas viagens de Heródoto e o intuito de entender os motivos que levaram gregos e persas a guerrearem resultaram na obra intitulada Histórias, redigida em dialeto jônico, em um estilo simples e direto (Waters, 1996: 28). Essas viagens, no início, não teria o objetivo específico de uma pesquisa histórica (Asheri; Lloyd; Corcella, 2007: 07), e não sabemos quando Heródoto concebeu a ideia de compor suas Histórias ou alguma composição literária como afirma Hart (1982: 162).

A região onde Halicarnasso estava localizada permitiu um encontro da cultura grega e da oriental e esse contato proporcionou o florescimento

\footnotetext{
$2 \mathrm{O}$ primeiro dado que gera discordância entre os historiadores através da leitura que realizamos é o que se refere à data de nascimento de Heródoto, que segundo $\mathrm{K}$. $\mathrm{H}$. Waters (1996: 10), A. D. Godley (1990: vii), John Hart (1982: 158) e John L. Myres (1999: 03), teria sido em 484 a.C.. Por outro lado, há estudiosos que aceitam outras datas: Cynthia Morais (2004: 15) e François Hartog (1999: 32) optaram pela data de 480 a.C., e Claude Orrieux e Pauline Pantel a de 485 a.C. (2004: 221). Para Waters (1996: 10), a data de 484 a.C. teria sido escolhida porque o período auge aproximado da vida do historiador grego, convencionalmente a idade de 40 anos, esteja ligada a data de fundação de Túrio ${ }^{2}$ (um evento datado de 444-3 a.C.) e, dessa forma, calculou-se a data de seu nascimento. Já Asheri (Asheri; Lloyd; Corcella, 2007: 05) nos informa de outro cálculo para a datação do nascimento de Heródoto: segundo autores antigos, Heródoto teria 53 anos quando a Guerra do Peloponeso estourou no ano de 431 a.C., ou seja, somando-se as duas datas, teremos o ano de 484 a.C.
} 
do pensamento racional e inquisitivo, tornando possível que os filósofos procurassem uma compreensão diversa da do mito para as manifestações da natureza (Morais, 2004: 20). A primeira aplicação do pensamento racional teria sido feita por Tales de Mileto, no ano de 585 a.C., na predição de um eclipse.

Waters (1996: 23) afirma que essa predição foi possível porque Tales tinha conhecimento das observações astronômicas realizadas pelos babilônios, que foram a base de seu estudo. Essa região jônica também produziu resultados em outros campos além da filosofia. Através do conhecimento de geometria dos egípcios, Anaximandro produziu, em 499 a.C., o primeiro mapa do mundo. Podemos perceber, dessa forma, como a influência oriental serviu de base para o desenvolvimento das ciências no mundo grego. Essa influência da racionalidade está presente em Heródoto, uma vez que, a tradução da palavra totopia ${ }^{3}$, título da obra, é investigação. Como ressalta Arnaldo Momigliano (2004: 60), o historiador grego optou por registrar os costumes e os acontecimentos de diversos povos através do exame crítico desse registro, quando ele acreditava ser oportuno. Essa racionalidade está presente, por exemplo, na passagem de sua viagem ao Egito, quando decide medir, com a ajuda dos guias, a pirâmide de Quéfren (Hdt., II.127).

Devemos, nesse momento, atentar para o fato de Heródoto ter escrito Historias em jônico, e não na língua cária ou dórica, idiomas comuns em sua polis. Ele estaria familiarizado com esse dialeto, que era utilizado em documentos oficiais da época, e reconhecido como uma língua literária desde Homero (Waters, 1996: 26; Asheri; Lloyd; Corcella, 2007: 03). Halicarnasso era uma cidade portuária, como já mencionamos, e, por isso, pode ter sofrido uma influência linguística e cultural de comunidades jônicas do norte. Entretanto, como salienta Godley (1990: XVI), Heródoto também fez uso de muitas palavras e formas que são associadas à literatura da Ática. Para o autor, talvez, a estada do historiador grego em Atenas tenha influenciado a redação de seu texto. Por outro lado, o uso das palavras escritas em jônico e ático antigo se torna, em alguns momentos, tão parecido que fica difícil perceber claramente a linha divisória entre elas.

Os acontecimentos narrados em sua obra também podem nos ajudar a estabelecer as datas de início e fim do processo de escrita pelo qual o historiador passou e que terminaria nos eventos descritos referentes aos

\footnotetext{
3 A palavra totopia somente passou a significar o estudo dos acontecimentos do passado após o século IV a.C. (Asheri; Lloyd; Corcella, 2007: 08), ou seja, um século depois de Heródoto.
} 
primeiros dois anos da Guerra do Peloponeso (431-30 a.C.), o que nos leva a crer que ele tenha deixado de escrever logo após esses acontecimentos. Segundo a tradição, Heródoto certamente esteve em Atenas para a leitura pública de sua obra, que era a forma de publicação das obras naquela época, em 445-4 a.C., recebendo por isso a soma exorbitante de 10 talentos (Momigliano, 2004: 66; Morais, 2004: 15; Asheri; Lloyd; Corcella, 2007: 04).

Myres (1999: 12) salienta que talvez a obra não estivesse completa quando ocorreu a leitura para a Boulé ateniense. Heródoto deve ter escrito o corpo principal da sua obra por volta dos anos 440-30 a.C. ${ }^{4}-\mathrm{e}$, de acordo com Momigliano (2004: 67), isso pode ter acontecido em Atenas - um período considerável para a inserção de outros logoi que Heródoto acreditava serem importantes para alcançar o intuito de sua composição. Nesse ponto, devemos ressaltar que a audiência da obra deveria ser o público heleno, e esse fato poderia influenciar na maneira como a obra foi pensada e composta, e como ele descreveria certas sociedades, costumes, leis e também as mulheres, sendo essa última categoria o foco desse artigo.

Muitos historiadores discordam do momento em que a obra tenha sido dividida em nove livros. De acordo com Asheri (Asheri; Lloyd; Corcella, 2007: 11), foi na tradição manuscrita medieval que essa divisão aconteceu, recebendo, cada livro, um nome de uma musa, seguindo a ordem canônica fundada em Hesíodo: Clio, Euterpe, Tália, Melpômene, Terpsícore, Érato, Polímnia, Urânia e Calíope. Para François Hartog (1999: 33), o nome das Musas não é atestado como título dos livros de Heródoto antes do século II d.C., e Hartog segue afirmando que essa inclusão das Musas demonstra como o texto do historiador grego era recebido: "está ao lado... da poesia, do prazer e da ficção".

Em sua obra, Heródoto aborda diferentes assuntos - não somente políticos, mas também no que tange às construções e costumes de outros povos - que, em determinados momentos, acabam fazendo o leitor se perguntar qual o objetivo do texto. Em alguns momentos, temos a impressão de que Heródoto escreveu logoi separados e que posteriormente foram agrupados, muitas vezes apresentando cortes abruptos entre um livro e outro.

No contexto do século $\mathrm{V}$ a.C., a única narrativa histórica possível de ser elaborada era aquela do conhecimento imediato, uma história do tempo

\footnotetext{
4 Para Cynthia Moraes (2004: 15), a obra teria sido escrita por volta de 446-5 ou 445-4 a.C.
} 
presente, segundo Jorge Lozano (1994: 19). O historiador narra os episódios que viu com os próprios olhos ou relata os acontecimentos a partir de alguém que os tenha testemunhado. Essa afirmação de Lozano fica evidente nessa passagem retirada do logos egípcio: "Até aqui, o que foi dito deriva do que vi, julguei e investiguei; a partir de agora, vou falar das histórias egípcias que ouvi e acrescentei alguma coisa que eu mesmo vi" (Hdt., II.99). Para Momigliano (2004: 62), Heródoto deixa claro em sua narrativa o limite entre a observação pessoal, eu vi, e as suas fontes orais, eu ouvi.

Caso Heródoto fosse considerado um viajante, não se deveria estranhar que as passagens encontradas em sua narrativa surgissem tanto da própria visão quanto da audição. Quanto aos relatos orais, de acordo com Lozano (1994: 19), poder-se-ia supor que eles não teriam o mesmo peso que o testemunho pessoal, pois a memória dessa outra pessoa, algumas vezes, não seria confiável. Porém, o historiador grego reforça, em alguns momentos, a credibilidade de suas fontes, assinalando, quando pertinente, que seu informante é capacitado para descrever aquele tipo de informação e essa postura, versa Momigliano (2004: 63), é um dos pontos mais característicos do método crítico utilizado por Heródoto.

Entretanto, como salienta Pedro Paulo Funari (2003: 18), devemos estar conscientes da subjetividade intrínseca ao relato histórico a partir do momento da concepção de que "todo o conhecimento expressa-se, necessariamente, como um discurso", enfatizando mais ainda a preocupação em se saber quem é o autor e a qual público a obra se destina. No tocante ao raciocínio de Jean-Pierre Vernant (2010: 55), uma das características da polis ateniense era a publicidade do conhecimento que antes se restringia a tradições familiares, ou a textos que pouco circulavam entre a população. Retomando a afirmação feita pelos historiadores de que Heródoto leu o seu discurso para os atenienses, podemos inferir que o seu destinatário eram os helenos, e não os povos relatados em sua obra.

\section{A descrição das personagens femininas no logos egípcio}

O segundo livro da obra Histórias informa o leitor, logo no início, que Cambises, filho do rei persa Ciro, havia herdado o império do pai recémfalecido e, a partir do momento que congregaria todo o exército e os escravos conquistados pelo pai, iria realizar uma expedição militar contra o Egito (II.1). Essa passagem nos remete às informações 
elaboradas pela historiografia sobre o contexto político da região no século V a.C.: Cambises teria invadido o Egito em 525 a.C. e os persas estariam no poder desde esse período.

Após se deter em assuntos políticos, Heródoto passa a descrever o rio Nilo, as terras cultiváveis, a extensão territorial da terra dos faraós e suas fronteiras até, no capítulo trinta e cinco, explicitar a escolha do Egito como local a ser conhecido e relatado em sua obra: "Ao mesmo tempo em que o clima egípcio é diferente, o rio apresenta uma natureza contrária àquela de outros rios, e de fato muitas leis e costumes se estabelecem contrários aos dos outros homens" (Hdt., II.35). A partir dessa passagem, encontramos diversos momentos em que as mulheres egípcias são representadas em diversos contextos históricos e sociais. Selecionamos algumas passagens importantes para a análise de nossa hipótese de trabalho nesse artigo, entretanto, ressaltamos que as egípcias aparecem em diversos capítulos do segundo livro.

Temos como hipótese de trabalho que Heródoto, ao registrar o comportamento feminino nas regiões que ele visitou, usa um filtro cultural grego, acentuando as diferenças significativas entre o mundo helênico e os outros povos, ou seja, como ressalta Hartog (1999: 229) "o mundo em que se conta e o mundo que se conta". Devemos ressaltar o fato de que ele possa ter lido a sua obra em público em Atenas, ou seja, a sua narrativa teria uma audiência particular, os helenos, e a maneira como ele descreveria as mulheres não poderia destoar das opiniões de seu público.

O primeiro trecho selecionado diz respeito aos papeis sociais que homens e mulheres desempenhavam na região egípcia:

Por um lado as mulheres vão à ágora e realizam o comércio, por outro lado os homens que ficam em casa tecendo (...) as mulheres urinam em pé, os homens, sentados (...) a mulher não pode ser sacerdotisa de nenhum deus ou deusa, os homens podem ser sacerdote de ambos. Os filhos não são obrigados a alimentar os pais, mas as filhas devem fazê-lo, embora não tenham vontade. (II.35).

De acordo com Donald Lateiner (1989: 147), o que marca o relato etnográfico que o historiador faz no Livro II, nos capítulos de 1 a 99 é justamente a polaridade nas suas investigações, chegando a afirmar que todos "os logoi herodoteanos são etnocêntricos, com os gregos no centro da análise". Para Alan B. Lloyd (Asheri; Lloyd; Corcella, 2007: 219), a distinção entre os gregos e os bárbaros, e nesse caso os egípcios, está no emprego da percepção das diferenças culturais que não são julgadas ou reprovadas pelo autor. Quando Heródoto, na passagem II, 35, afirma que 
os egípcios, seus costumes e os regimes dos rios diferem de todos os outros povos, o historiador grego apenas informa seu público essas diferenças. A partir dessa premissa, ele expõe as diferenças entre os papéis desempenhados por homens e mulheres no Egito, chegando a afirmar que as mulheres urinavam em pé ou realizavam o comércio, o que constituía, para os atenienses, um comportamento que deveria ser praticado somente por homens.

Essa descrição nos permite demonstrar que ao relatar a mulher egípcia, podemos imaginar, de maneira oposta, qual seria o papel que as mulheres gregas deveriam desempenhar em sua sociedade. Heródoto carregaria elementos gregos na sua viagem, e essa influência perpassaria todas as descrições etnográficas de sua obra, como ressalta Richard McNeal (1988: 54). Esse comportamento das mulheres poderia servir como um exemplo da falta de características gregas nos egípcios, como versa Lateiner (1989: 149). Há um sistema de comparação no qual a cultura grega é comparada com a cultura egípcia, e os valores e a motivação dos indivíduos gregos são reiterados para o seu público heleno a cada novo contraponto. Heródoto deixa explícito essas diferenças culturais e sociais entre esse dois povos quando afirma que os egípcios "evitam adotar os costumes dos helenos. Na verdade, evitam qualquer costume de qualquer outro povo." (Hdt., II.91).

Analisando o discurso de Heródoto, conseguimos imaginar as mulheres atenienses levando em consideração a afirmação de McNeal (1988: 71) de que a obra herodoteana explica muito mais a cultura grega do que a dos outros povos. Ao descrever as egípcias, considerando a questão da alteridade de Hartog (1999: 316), ele reconstrói, a partir de um movimento de inversão, a mulher ateniense, que não vai ao mercado, pois ficaria em casa tecendo. Para isso, é necessário que a comparação seja feita através de elementos conhecidos em seu mundo, o heleno, estabelecendo entre as duas partes da comparação, semelhanças e diferenças. Nesse caso, percebemos somente diferenças entre o mundo grego e o egípcio, entre o eu e o outro.

Os papéis masculino e feminino, que deveriam ser desempenhados dentro da polis, são constituídos pelas características que permeiam cada gênero naquele momento. De acordo com Marta Mega de Andrade (2003: 116), as identidades sociais são "moldadas pelo atributo do gênero". Lourdes Feitosa (2005: 22) complementa essa afirmação, pois para ela esse comportamento, que cada gênero deveria desempenhar, é influenciado pelas relações culturais articuladas entre eles. Em outras palavras, o discurso presente na sociedade polariza os gêneros e agregalhe características antagônicas, havendo uma fabricação do gênero, mas 
que somente ocorre através da relação entre homens e mulheres dentro dessa sociedade. Talvez seja por esse motivo que o historiador grego agrega um atributo masculino as mulheres - elas urinam de pé - e feminino para os homens - os homens, sentado. Ao fim dessa passagem, pela inversão dos papéis, delineamos como os gêneros se relacionavam dentro da polis ateniense, pois no discurso está evidente qual a atuação social de cada um.

As atividades concernentes às mulheres na época de Heródoto eram aquelas menos visíveis, como as que se limitavam dentro das casas. De acordo com Sara Pomeroy (1999: 90-91), as mulheres das classes mais abastadas não podiam trabalhar; sua obrigação era se preocupar em guardar a casa e cuidar dos filhos. Seu círculo de contato com pessoas abrangia, além do marido e dos filhos, seus pais, irmãs, alguns parentes mais próximos e os criados. A imagem das mulheres reclusas em um quarto de habitação que lhe era reservado, o chamado gineceu, atualmente não é mais aceita. Todavia, para essa autora, elas tinham poucas relações com o mundo exterior. Para Gould (1980: 48), as atenienses abastadas teriam uma escrava que faria o serviço para o qual fosse necessário sair de casa, como buscar água nas fontes, evitando dessa forma que as atenienses se encontrassem com homens desconhecidos, que poderiam proporcionar, de acordo com Fantham et al. (1994: 103), uma ameaça para a sua castidade e legitimação dos herdeiros.

Embora a exclusão rigorosa raramente tivesse sido colocada em prática, como versa Pomeroy (1999: 89), está claro que tanto ideologicamente quanto na vida real, a casa era a esfera predominante do trabalho da mulher. Todavia, o trabalho doméstico feminino era considerado com um baixo valor social. Desde o momento em que um trabalho era depreciado, também o era quem o realizava. O trabalho das mulheres era produtivo, porém, ao ser semelhante ao dos escravos, acabava não sendo valorizado. As mulheres eram postas a fiar e a tecer, trabalhos que todas haviam aprendido com suas mães e fazia parte da educação de uma futura esposa, que vigiaria as suas escravas domésticas. A inversão dos atributos pertencentes aos homens e às mulheres também se torna evidente na passagem selecionada no momento em que Heródoto descreve que o trabalho de tecelagem ficaria a cargo dos homens egípcios.

Se considerássemos somente essa passagem de Heródoto, acreditaríamos que as mulheres atenienses permaneceriam dentro de casa, cuidando dos seus afazeres domésticos. Entretanto, apesar das mulheres das camadas mais abastadas serem raramente representadas 
fora das casas, elas estão presentes em festivais, em cemitérios e em procissões de casamentos (FANTHAM et al, 1994: 79). Por não ser estranho aos olhos de Heródoto, as mulheres participarem dos rituais fúnebres, ele descreve como tais rituais eram realizados no Egito, sem explicitar a sua opinião a respeito desse assunto:

Os seus cantos de lamentação e funerais são os seguintes: entre eles, quando morre um homem da família que seja importante, todas as mulheres da casa untam a cabeça ou o rosto com lama, em seguida, depois deixando o cadáver em casa, as mulheres circulam pela cidade golpeando em si mesmas, com as roupas até a cintura e mostram os seus seios. (II.85).

Os cultos mortuários estão presentes nas decorações de diversas tumbas egípcias desde o Antigo Reinado. De acordo com Asheri, apesar das fontes acerca dos rituais realizados após a morte de um parente serem muito anteriores a Heródoto, "é perfeitamente plausível que tal prática, ou ao menos uma tendência geral, existisse no século V a.C." (Asheri; Lloyd; Corcella, 2007: 298).

Concordamos com Sue Blundell (2001: 126) quando ela afirma que as mulheres atenienses também poderiam ser vistas nos rituais funerários. Nesse caso, segundo Fantham et al. (1994: 76-7), Sólon também teria regulamentado a forma como esse ritual deveria ser conduzido, e que somente parentes próximos do morto poderiam velá-lo, recomendando também restrição na lamentação em público; em outras palavras, uma tentativa de cercear o contato das mulheres com outros homens apartados do seu círculo familiar.

No capítulo 92 do livro II, Heródoto volta a comparar helenos e egípcios, ao afirmar que "os que habitam os pântanos úmidos do Egito praticam os mesmos costumes que os demais egípcios e, entre outros, cada um deles vive com uma única mulher, como os helenos..." (II.92). Asheri afirma que Heródoto optou por narrar "uma prática padrão, em vez de toda uma gama de opções legais que ocorreriam no Egito". (Asheri; Lloyd; Corcella, 2007: 304).

Segundo a historiografia a respeito da Grécia Clássica, a coabitação é necessária para fazer da jovem filha uma gamete gune, uma única esposa legítima, como descreveu Heródoto. O casamento jamais é uma livre escolha por parte da jovem mulher, principalmente em situações onde haveria um acordo entre famílias. $\mathrm{O}$ objetivo do casamento era a procriação de filhos legítimos destinados a herdar os bens maternais e ele estava, portanto, ligado ao regime da propriedade e da sucessão dos bens patrimoniais (Mossé, 1991: 52). 
Entretanto, nem sempre essas regras de comportamento eram seguidas, e foram criadas normas para definir as punições cabíveis para homens e mulheres praticantes do adultério. A palavra grega moicheia, ou adultério, como ressalta Blundell (1994: 125) apresenta muitos significados. Ela poderia ser traduzida como manter relações amorosas não autorizadas com mulheres que tinham um guardião ateniense e que não trabalhavam como cortesãs ou acompanhantes. De acordo com a autora supracitada (1994: 125), os homens não tinham a liberdade para se relacionar sexualmente com quem quisessem, sendo a moicheia uma ofensa punível. Caso um cidadão pegasse um homem no ato sexual com uma mulher sob sua tutela, ele tinha o direito de matá-lo naquele momento. Outra possibilidade seria que o amante oferecesse uma compensação financeira - o que o tornaria prisioneiro até que provesse as garantias da soma acordada entre eles - ao outro homem, ou poderia, ainda, infligir humilhações corporais variadas ao amante. Se o tutor não tivesse sucesso em pegar o casal em flagrante, ou se ele tivesse decidido não tomar qualquer atitude particular, ele ainda teria a opção de iniciar um processo por sedução ou violação.

As leis atenienses tentavam, dessa forma, regulamentar a vida amorosa da sua população. Segundo Fantham et al. (1994: 73), os homens atenienses podiam ter e tinham concubinas. Porém, após a lei de cidadania de Péricles de 451-450 a.C., os filhos com concubinas não teriam mais o direito de participar das assembleias ou dos rituais religiosos oficiais da polis. Assim sendo, a lei garantiria aos filhos legítimos a manutenção dos seus direitos políticos, o que poderia ser considerado uma das distinções entre a mulher legítima e a concubina no interior da polis ateniense.

Essa questão envolvendo os filhos que seriam legítimos, e, dessa forma, poderiam participar da vida política, remete-nos à última passagem selecionada. Heródoto, no capítulo 99, anuncia que, a partir daquele momento, contaria "os relatos dos egípcios, conforme eu os ouvi deles" (II.99). Desse momento em diante, o autor começa a descrever a História do Egito, iniciando pelo primeiro faraó, Min (Menés). Entre as palavras dele, uma informação nos chama a atenção: “Entre tão numerosas gerações de homens... uma única rainha nata... O nome dessa mulher, que tem o mesmo nome daquela que reinou no território da Babilônia, era Nitócris5." (II.100).

5 Ao consultar as diversas obras que se debruçaram a respeito da narrativa de Heródoto, podemos inferir que, provavelmente, ele deve ter se confundido com relação ao nome das rainhas, ou um erro de tradução entre o relato do faraó e a compreensão do tradutor que auxiliaria Heródoto. De qualquer maneira, a origem de Nitócris não 
Provavelmente, uma rainha no Egito também teria despertado a curiosidade de Heródoto. A democracia ateniense, sistema político contemporâneo ao período de escrita das Histórias, excluía as mulheres do exercício do voto e de entrar no recinto da assembleia. Essa cidadania democrática, tal qual se define durante o século de Péricles, excluindo as mulheres do poder político, não esgota as possibilidades de relação íntima com a pólis, como a geração de filhos legítimos e a manutenção da memória dos antepassados.

Não é somente o fato de uma mulher poder ocupar o mais alto cargo político de uma sociedade que se destaca nessa passagem, mas também a atitude que a rainha Nitócris, de acordo com o relato dos sacerdotes egípcios, empreende para vingar a morte do irmão pelos egípcios. Assim narra Heródoto:

... ela fez construir um recinto subterrâneo enorme e... elaborava outras intenções em sua mente; e ela convidou os egípcios para esse local... recebendo muitos convidados, enquanto eles se banqueteavam, o rio avançou por um enorme canal escondido. Eles não relataram outros acontecimentos, exceto que ela mesma, depois desse fato, atirou-se em um recinto cheio de cinza para evitar uma vingança. (Hdt., II.100).

Pelas palavras do historiador grego, podemos notar que Nitócris elaborou uma engenhosa vingança, que necessitou de planejamento e tempo para ser executada, elaborava outras intenções em sua mente e não demonstrava arrependimento pela morte dos egípcios. Em nenhum momento, nessa passagem, encontramos a opinião dos sacerdotes sobre esse episódio. De acordo com as palavras de Ove Strid (2006: 403), Heródoto está interessado nas circunstâncias que envolvem a morte da vítima, evitando narrar o ponto de vista da mesma. O importante é descrever o processo da morte, especialmente se ele for extraordinário e maravilhoso, não havendo diferença se a morte ocorreu no campo de batalha ou por vingança.

\section{Considerações finais}

Podemos perceber nessas cenas egípcias a construção dos códigos culturais mediados pelas representações dos papéis sociais através das atribuições concedidas a homens e mulheres em diferentes lugares e contextos históricos. Através do relato de Heródoto, foi possível inferir muitas outras informações sobre as egípcias: que elas trajavam somente

anula sua importância para a confecção das Histórias e para a nossa análise nesse artigo. 
uma vestimenta (II.36), ou seja, um vestido de linho que é representado na iconografia das tumbas egípcias, que negociavam suas mercadorias no mercado (II.35), participavam dos rituais funerários (II.85) e poderiam até se tornar rainhas (II.100). Ao mesmo tempo, essas descrições nos permitem demonstrar - ao relatar a mulher egípcia, podemos imaginar, de maneira oposta - qual seria o papel que as mulheres gregas deveriam desempenhar em sua sociedade, uma vez que o historiador grego carregaria elementos gregos na sua viagem pelas diversas regiões do mundo habitado.

Acreditamos que os trechos selecionados para este texto estejam permeados pelos recursos da construção do outro e, dessa forma, conseguimos delinear o parâmetro de um comportamento feminino, no qual as mulheres atenienses deveriam observar em seu cotidiano, através da descrição da atuação das mulheres egípcias. Entretanto, a partir da narrativa de Heródoto, também conseguimos perceber a diversidade das práticas femininas dentro das sociedades descritas por ele.

Esse pequeno esboço a respeito do logos egípcio presente na obra Histórias nos alerta para a ideia de que as mulheres teriam um comportamento definido dentro da sociedade ateniense e que ele deveria ser adotado nas famílias e respeitado pelas próprias mulheres. Todavia, não acreditamos que as mulheres atenienses tivessem um comportamento passivo no tocante a sua presença na esfera pública e, se aceitamos a teoria de alguns historiadores de que Heródoto tenha vivido alguns anos em Atenas, não seria espantoso, para ele, encontrar mulheres exercendo outras atividades fora do oikos nessa polis. Porém, o teor do seu relato acaba reforçando a nossa hipótese de trabalho, que ele adote um modelo de comportamento feminino a ser seguido pelas mulheres.

Dessa forma, percebemos que os papéis de gênero construídos pelo discurso masculino no caso da Antiguidade, em que há estipulado que cada sexo, de acordo com suas características físicas, é responsável por tarefas específicas dentro da cidade-estado, como a tecelagem para as mulheres e o comércio para os homens, nem sempre condicionam as ações femininas praticadas nas diferentes esferas sociais. Em outras palavras, os historiadores, ao analisarem as suas fontes, devem atentar para a pluralidade das atuações masculinas e femininas nas sociedades estudadas (Sebillotte-Cuchet; Ernoult, 2006: 12).

Assim, Scott (1986: 1056) nos convida a refletir sobre as diferentes práticas exercidas pelos homens e mulheres nos diferentes contextos 
históricos e a respeito de suas relações estabelecidas dentro de uma determinada sociedade. A categoria de gênero, como afirma a autora (1986: 1054), permite-nos afirmar que esse comportamento ideal feminino nasce das mediações entre homens e mulheres na sociedade e que resultarão na definição de quais papéis sociais são designados para cada um dos sexos em uma determinada localidade, em um contexto específico. Nesse texto, não procuramos evidenciar como esses gêneros são representados nas produções discursivas, pois não podemos considerar que homens e mulheres vivessem completamente em esferas separadas na sociedade ateniense.

O estudo de gênero no logos egípcio de Heródoto nos revelou, a partir da temática da alteridade, o leque de identidades e construções de papéis sociais dentro da sociedade ateniense, que são discursos perpassados pela subjetividade e pelas relações de poder (Funari, 2008: 102-3), que devem ser lidos e interpretados pelos historiadores. De acordo com Jenkins (2005: 33), conhecemos o passado através das perguntas que fazemos ao nosso presente, ou seja, a história é um discurso em constante transformação, pois a emergência de novos símbolos culturais (Scott, 1986: 1074) provoca novas reinterpretações do passado. Assim sendo, as conclusões apresentadas neste artigo configuram uma maneira de se interpretar as fontes antigas, mesmo aquelas que já foram esmiuçadas por diversas pesquisas ao longo dos séculos, como é o caso da obra Histórias, elaborada pelo pai da História.

\section{Fontes}

HERODOTE. Introduction, notice preliminaire sur la vie et la personnalité d'Herodote et sur la presente edition par E. Legran. Paris, Belles Lettres, 1932.

HERODOTUS. With an English translation by A. D. Godley. Cambridge, Mass.; London: Harvard Univ.: Heinemann, 1990.

\section{Referências bibliográficas}

ANDRADE, Marta Mega de. A "Cidade das Mulheres": a questão feminina e a polis revisitada. In: FUNARI, Pedro Paulo; FEITOSA, Lourdes Conde; SILVA, Glaydson José da (Orgs.). Amor, desejo e poder na 
Antigüidade: relações de gênero e representações do feminino. Campinas: Editora da Unicamp, 2003.

ASHERI, David; LLOYD, Alan; CORCELLA, Aldo. Herodotus Books I-IV. Oxford, Oxford University Press, 2007.

BLUNDELL, Sue. Women in ancient Greece. Cambridge, Mass.: Harvard University Press, 1995.

BRIANT, Pierre. From Cyrus to Alexander: A history of the Persian Empire. Winona Lake, Indiana: Eisenbrauns, 2002.

Hérodote et la société perse. In: REVERDIN, Olivier; GRANGE, Bernard. Hérodote et les peuples non grecs. Genève: Vandoeuvres, 1988.

FANTHAM, Elaine; FOLEY, Helene Peet; KAMPEN, Natalie Boymel; SHAPIRO, H. A. Women in the Classical World. New York: Oxford University Press, 1994.

FEITOSA, Lourdes Conde. Amor e Sexualidade: o masculino e o feminino em grafites de Pompéia. São Paulo: Ed. Annablume, 2005.

FUNARI, Pedro Paulo A. Antiguidade Clássica - a história e a cultura a partir dos documentos. Campinas, Ed. Unicamp, 2003.

. Gênero e conflitos no Satyricon: O caso da Dama de Éfeso. História: Questões e Debates, Curitiba, n. 48/49, p. 101-117, 2008. Editora UFPR.

GOULD, John. Law, Custom and Myth: Aspects of the Social Position of Women in Classical Athens. The Journal of Hellenic Studies, Vol. 100, Centenary Issue, p. 38-59, 1980. Acesso em: 12/08/2010.

HART, John. Herodotus and Greek History. New York: St. Martin's Press, 1982.

HARTOG, François. O espelho de Heródoto: ensaio sobre a representação do outro. Belo Horizonte: Editora UFMG, 1999.

HERÔDOTOS. História. Tradução do grego, introdução e notas de Mário da Gama Kury. Brasília: Ed. Universidade de Brasília, 1985.

HERÓDOTO: Histórias: O relato clássico da Guerra entre Gregos e Persas. Trad. J. Brito Broca. São Paulo: Ediouro, 2001. 
JENKINS, Keith. A História repensada. São Paulo: Ed. Contexto, 2005.

LATEINER, Donald. The Historical Method of Herodotus. Toronto: University of Toronto Press, 1989.

LOZANO, Jorge. El discurso histórico. Madrid: Alianza Editorial, 1994.

MCNEAL, Richard A. The Brides of Babylon: Herodotus 1.196. Historia: Zeitschrift für Alte Geschichte, Vol. 37, n. 1, p. 54-71, 1st Qtr., 1988.

MOMIGLIANO, Arnaldo. As raízes clássicas da historiografia moderna. Trad. Maria Beatriz B. Florenzano. Bauru, S.P.: EDUSC, 2004.

MORAIS, Cynthia. Maravilhas do Mundo Antigo: Heródoto, pai da História? Belo Horizonte: Editora UFMG, 2004.

MORAES, Érica Siane. Heródoto e o Egito. Tradução e comentário do Livro II das Histórias. Dissertação de Mestrado. Campinas, 1999.

MOSSÉ, Claude. La femme dans la Grece Antique. Bruxelles: Éditions Complexes, 1991.

MYRES, John L. Herodotus, father of history. Oxford: Clarendon Press: Sandpiper Books, 1999 (1953).

ORRIEUX, Claude; PANTEL, Pauline Schmitt. Histoire grecque. Paris: Presses universitaires de France, 2004.

POMEROY, Sara B. Diosas, rameras, esposas y esclavas: mujeres en la Antigüedad Clásica. Madrid: Ediciones Akal, 1999.

SCOTT, Joan. Gender: A useful category of historical analysis. The American Historical Review. Vol. 91, n. 5, p. 1053-1075, Dec., 1986.

SEBILLOTTE-CUCHET, Violaine; ERNOULT, Nathalie. Problèmes $d u$ genre en Grèce ancienne. Paris: Publications de la Sorbonne, 2007.

STRID, Ove. Voiceless victims, memorable deaths in Herodotus. Classical Quarterly, vol. 52, n. 2, p. 393-403, 2006.

VERNANT, Jean-Pierre. As Origens do Pensamento Grego. Rio de Janeiro: Editora Difel, 2010. 
VIVERO, Manuel Albaladejo. Crueldad y violencia en los personajes femeninos de Heródoto. Emerita, vol. LXXV, n. 2 (julio-diciembre), 2007, p. 299-317.

WATERS, K. H. Heródoto El historiador. México, Fundo de Cultura Economica, (1985) 1996. 